\title{
BOARD-BASED LEARNING EXPERIENCE: A PRACTICAL APPROACH TOWARDS THE IMPROVEMENT OF STUDENTS' INFORMATION LITERACY INTEREST AND ACADEMIC RESULT
}

\author{
Anisa Nurfaidah ${ }^{1}$ \\ SDN 005 Babakan Ciparay Kota Bandung ${ }^{1}$ \\ anisanurfaidah21@gmail.com
}

\begin{abstract}
APA Citation: Nurfaidah, A. (2020). Board-based learning experience: A practical approach towards the improvement of students' information literacy interest and academic result. Language Research in Society Journal, 1(1), 8-17.
\end{abstract}

Received: 19 March 2020

Accepted: 06 April 2020

Published: 02 May 2020

\begin{abstract}
Teaching information literacy has always been a challenging issue to tackle. Classical teaching and learning activities require students to sit, to read, to understand and to be able to answer questions to meet the minimum accomplishment criteria. To undergo joyful learning, this board-based learning experience has enabled the teacher to manifest varied teaching strategies despite the limited resources and also to facilitate students to develop their reading, communication, and social skills. The findings of this study indicate that this experience has represented positive impacts toward the improvement of students' information literacy interest and academic results. Not only relatively livelier learning experience, it has stimulated students to use mind map strategy to locate keywords and to link them with details in an informational text, resulting in the progress of the individual score progress by average which reached 21.67 points. Special notes should be addressed to the teachers or other practitioners that we should always give attention to students to find ways to connect main ideas, supporting ideas and blend them into the context. As the conclusion, the teacher should be able to enhance their teaching skill by integrating any teaching strategies.
\end{abstract}

Keywords: information literacy; reading comprehension; joyful learning; teaching strategies

\section{INTRODUCTION}

The change in our national curriculum has always been a major issue in our educational system. Teachers are compelled to adapt to the change immediately. Materials that were explained separately in diverse subjects before are now supposed to be delivered within the same theme. This caused numerous challenges such as the difficulty to infuse materials in one topic and to deepen the proficiency of each subject available in written forms.

\section{Coping with information illiteracy issue}

A real-time challenge that educational practitioners are facing dealing with written forms is the delivery or the process and the assessment of students' reading comprehension skills in each theme. Every month will commence with a new theme, new particular topics to deliver and to be answered with informational texts found everywhere in many sections of the book. It may be concluded that it has become an essential matter our young students should be able to master and understand why they always exist. As the participants' ideas of being information literate are a major consideration in defining information literacy and the ideas change over time and environment (Walsh, 2011), teachers should also put attention on giving understanding and support for students not to easily give up on them as they will gradually discover a lot of topics to comprehend. 
During the fourth year in primary school, students have already been exposed to academic vocabulary. Informational text related to science, citizenship, literature, and socio-culture is included entirely in the same scope. Since information literacy is the ability to find, evaluate, and use information efficiently, effectively, and ethically to answer an information need (Lanning, 2012), that would mean students ought to spend more time to comprehend each word that is written together in unfamiliar, different patterns and structures then portrayed it in a new theme which sometimes fails to grab their interests. They should spend more time to conclude what the informational texts about and determine its meaningful context.

The teacher observes the circumstance and it obviously shows that students face challenges in understanding the language they read as it is different from the one they speak every single day and on any informal conversations where they are usually engaged in. It is quite different from the amusing information they read in fictional books or any topics related to their daily life. Either it is delivered in their native language or Indonesian. The difference is so distinctive, they discover a lot of new vocabularies to comprehend and more complex grammatical structures to analyze at the same time. And thus, making students relatively find it difficult to understand quickly as we have to swift from each 'subject' to another, sometimes, in the same session. The informational text doesn't provide a happily ever after ending, it is a sort of knowledge students have to cultivate and proceed in their mind, which makes them exhausted and bored.

To understand the text, students are supposed to be able to practice their literacy skills dealing with identifying, corresponding, drawing conclusion and related to academic target, answering questions correctly. It directs students to apply different techniques compared to their prior experience in reading. This phase requires guidance from teachers whose role is to provide them easy-steps practice and to facilitate their needs to relate prior knowledge they own, search the information they should analyze what it is about and inventory things they need to find out.

\section{Teachers' challenge}

In fact, teachers are still facing challenges in delivering informational text activities. Some of us still lack creativity, a fresh idea or breakthrough strategy even though it shouldn't be that complicated or using some sort of high technology tools. Some of us still tend to conduct classical reading activities by which they hope to improve students' literacy skills without regarding their psychological needs and cognitive needs as well. Lesson plans are designed according to the manual teachers' book, where a daily target is committed based on fixed basic competence that should be taught that day.

This activity aforementioned is not much well-aligned with a recent program launched by the government, The Ministry of Education, namely "Merdeka Belajar". Means, the teachers now have freedom and to plan their class activities to be as lively as they may be. There should be varied experiences added to classical teaching and learning activities which only require students to sit, to read, to understand and to be able to answer questions. Students will not merely read, but they will also attaint and develop their reading comprehension skills to meet the minimum accomplishment criteria. Furthermore, enjoying every single reading session.

On the other hand, the government has also made several efforts to support teachers to create a better and more interesting learning activity for students to experience as well. But what we observe that, despite all digital tools and applications which were invested, introduced, distributed and owned by the school, there are still major problems. The first one is related to the school's readiness to utilize them, primarily about electricity support. Some educational institutions may have low voltage electricity that they have to turn off other electrical appliances so others may run. Some of them lack sockets and other technical support. Another problem is 
the human resource capacity to operate where we must admit, not all teachers are digital and computer literate.

\section{The scope of this study}

This study was trying to sum up challenges related to the issue. It was aimed at exploring ways to create joyful learning and analyzing their impacts on students' information literacy interest and academic results in a primary institution despite any technical teaching problems. The focus was the different strategies used in the classroom to be provided as recommendations for peer teachers or other practitioners on using a variety of teaching strategies that would wellundergone with the expected learning outcomes.

The questions to be addressed from this study are the following:

1. Could this board-based learning experience improve students' literacy interest in comparison to classical teaching and learning activities?

2. Could this board-based learning experience improve students' academic results in comparison to classical teaching and learning activities?

\section{METHOD}

\section{Data sources:}

A qualitative approach using a descriptive case study design was conducted. It seeks the social context that can be systematically analyzed as a whole. The subjects of the study were 34 students from grade 4 of primary school. Classroom observation was the main method to collect data, while data analysis used thematic analysis.

\section{Materials and Instruments}

To guarantee the validity and reliability, the material chosen was based on the $3^{\text {rd }}$ and $4^{\text {th }}$ core competences (knowledge and skill competence). It was an enrichment material from the topic students should study in the class during a regular period and was considered difficult to understand as the material consisted of new scientific terminologies and concepts. Those about expository text typically demand answers about the main idea and supporting details, and the one chosen was an expository text which discussed waste. It was prepared by the teacher and consisted of sub-topics such as definitions, types of waste, waste management at school and at home, and recycling waste. Three instruments were used in data collection, namely: pre-test form, observation form, and post-test form. To compare the results of the two tests, the same questions were prepared for the post-test. The notes in the observation forms later were compiled and reviewed to identify facts and findings.

\section{Procedure}

To facilitate students with various learning styles and joyful learning, the teacher has arranged board-based learning activities that were planned according to Kolb's four types of learner (visual, auditory, read/write and kinaesthetic) equipped with step by step instructions, supporting materials and experience. Visual learners were facilitated with mind maps and wall magazines. Auditory learners would prefer discussion. Read/write learners would enjoy themselves taking notes. Kinaesthetic learners would choose to move around the class and to decorate wall magazines as their favorite parts. It was expected that this arrangement would activate senses and interests, as multisensory means just that: ways of appealing to all the senses (Blanchett et al. 2012).

\section{Pre-test}

To begin with, the teacher would display some pictures and videos related to the topic without any deep elaboration as classical reading activity was organized. Students were later told to read the text individually and answer the questions. A set of questions were given as the pre-test

10|Language Research in Society Journal, Vol 1(1), 2020 
form, which was aimed to measure students' reading comprehension within classical teaching and learning activities. The evaluation paper consisted of short answers, completing data in a table, and open-ended questions.

\section{Introduction session}

The practice of Kolb's theory started with the introduction session, where the teacher explained the reason why it was important to learn, to understand and to answer questions related to informational texts. Before the explanation, the teacher conducted brainstorming time to find out the class' prior knowledge. The teacher would also describe the process in which students were going to be involved as an individual, as a group, and as a whole class. Varied responses from students were expected to come up as reading activities were believed to be as joyful as other subjects. They were eager to see each other's interest in voluntarily giving opinions, sharing ideas, collaborating and supporting each other member. The teacher also might be able to identify how well students grasped a concept and how excellent they were in performing their skill and adjusting necessarily to the intended learning activities.

Grasping the main idea or keywords was the first procedure conducted in the classroom. Soon, students simply needed to practice their literacy proficiency skills by taking notes. It required the ability to categorize details for which the teacher should guide. To achieve this goal, the teacher played the same video about waste then asked students to think of what the video was about, write it on sticky notes and stick them on the board. Some students would come forward to read what their friends' conclusions were. Then the teacher wrapped a conclusion by dealing it with students, wrote the major topic on the board and led the class discussion by giving an oral illustration of keywords of a paragraph (first paragraph as the example) then giving some clues related to the main idea of the paragraph.

\section{Mind maps}

During this session, students still ought to read the same paragraph then tried to identify and locate more critical points of the content. They may start with any new vocabularies they found them difficult to understand. The teacher then related their identifications to what keywords were. Once students were getting the idea of those keywords, they would draw bubbles around their findings. The teacher would be using this opportunity to get students conveying the details of those keywords, using 'branch' to connect bubbles from the major one to the detailed ones. Each should be linked to seek for the correlation between. Students were instructed to read the whole paragraph and by the end of reading, students were guided to elaborate on the keywords they found and the sub-focus to be filled in the bubbles.

Text papers and other papers containing empty bubbles drawn on each side would be handed over to the class and the teacher was later to re-explain cues on how to notice the keywords. The next paragraph would be given to students to observe. They were expected to identify keywords as the main ideas of each paragraph, to brainstorm their opinions once the details were supposed to identify and to take notes when the ideas were fixed by filling in the bubbles provided. The bubbles were not ordinary, they were mind maps that could be used to help students determine important vocabularies, concepts, and keywords. Big bubbles as the fundamental focus represented bigger topics and smaller ones were designated as the description of the major concept they examined and they should always be placed in the center of the paper.

An extended mind map was allowed to create if any students needed to add any information they wished to locate by adding more 'branches' to each bubble. The teacher might encourage them by providing highlighters, markers, and stickers to attract more attention and interest toward the topics as well as to underline important notes each student wrote. 


\section{Group and class discussion}

The teacher had full authority to switch students' seating arrangements at this stage. Students' opinions and conclusions would construct the class moment of academic reflection. The motivation was to stimulate interest and to relate their prior knowledge to the topics they were dealing with. Making connections deepens students' comprehension and, if the connection is way too far from their daily life, personalize it. Students make three basic connections: text to text, text to self, and text to world (Gunning 2010). So students who came up with their keywords would have to share their opinions that best described the topic by following any knowledge they had already known.

When the teacher had questions, dominant students would always be taking control and seeking attention wherever they were. The teacher might ask further about how they handled waste at home, how they reduced plastic bags at school, et cetera. These questions might not be difficult, they should be grammatically simple, so that students could easily interpret the context and get involved in the class activities as quickly as possible. They wrote their sample keywords of each paragraph and sticky notes were needed to stick them on the board then the teacher would come to elaborate with their peers.

As information literacy sessions are likely to involve all three domains, but will normally focus on the cognitive domain - the acquisition and use of knowledge (Blanchett, et al. 2012), this activity might be challenging for students with lower reading capacity, either with lower speaking capacity as well. If any students were found or remained silent during this session, the teacher might prepare some hints, including more simple word and synonyms to help them go through this phase. They should always be reminded and encouraged to underline difficult words to understand, to be involved in the discussion and to speak up their opinions by connecting keywords to keywords. We might give them special opportunity to present their mind maps with special rewards awaiting if they succeeded.

This means we must reflect again on exploring strategies to improve students' self-esteem and confidence. It might be difficult for some students who were considered less social yet they were always encouraged to interact and complete the project together. Supporting, promoting and reminding the class that collaborative activities urged everyone to be involved and to contribute to the whole process. No matter how small their roles were, they were considered important and would affect the group's result.

This guided elaboration and brainstorming activity was conducted with the whole class, but the mind map-making was carried out individually. Each mind map was going to be taken forward to the group and led to a discussion. It was intended to get students to verbalize their findings, opinions, and conclusions in their minds related to the given topic. At the end of this session, each group should be able to finalize their mind map to be presented on the board, which they thought was going to be the most thorough mind map their group could ever present to conclude the whole member's opinions. The teacher ensured that each student knew and understood what they wrote, what they elaborated with friends so this experience was able to be considered reading comprehension activity.

It was an effective approach to assess students' reading comprehension skills by which the teacher might be able to check the depth and detail of the topic students were discussing. For this to consider as individual assessment, each mind map would be checked to see if students were seriously and actively taking notes during this session.

\section{Collaboration through wall magazines-making}

The next step would bring students into different learning experiences and atmosphere. This session was designed for the collaborative learning in which students were still divided into 
groups and were assigned to create wall magazines by using mind maps they had already created before. The teacher would assess students individually according to their mind maps, how they worked as a group to achieve common goals and how this project would be the feedback to the class program.

This was a structured form of group work that focused on delivering discussions, promoting various learning styles, encouraging each other, developing social, communication and cooperation skills. There were no group leaders, all members served the same responsibility with different divisions to work in. Some of them had to grasp the main ideas to be executed in the wall magazines, some of them had to write beautifully on the paper, some of them had to decorate, et cetera. By doing this type of activity, by having witnessed each other's character portrayed in their work, students would also learn the importance of maintaining a positive working atmosphere and respecting each other as an individual.

The board was now divided into several parts as students' wall magazines were then displayed on it as the center of attention in the class, placed separately and were provided quite a space from each other. 7 groups would take the turn to see the whole projects and discuss what they had seen. Each of them would be given an opportunity to examine other groups' final projects and to highlight some notes as feedbacks. They were handed pencils, paper, and sticky notes to mark the wall magazines. During this session, the teacher motivated students and tried to develop ways to enhance student critical thinking. Most important was, this experience has made students feel delighted during the whole process which was the main characteristic of joyful learning.

The overall process: encouraged peer-to-peer learning, working in groups, agreeing on the overall domain and understanding this bigger picture enabled students to develop and refine their thoughts about their individual topic and to place it in a wider context helped students develop their communication and presentation skills helped the students, the majority of whom did not speak English as their first language, to become familiar with the language of the domain. (Hepworth and Walton, 2009)

\section{Peer assessment}

By the end of this session, the teacher allowed each group to verbalize their opinions about other groups' projects and submit their marks by using sticky notes and sticking them onto the intended wall magazine. The teacher should explain the assessment criteria (such as clarity, details, design, decoration, et cetera) for this to work effectively, thus students would understand how they worked later to decide the number of points they would grant to other groups. The group which got the most point would be awarded special treats from the teacher.

\section{Post test}

The study ended with the post-test on the following day. All the sessions were held during a regular class period and in the regular classroom, taking 34 students (one class) as the subjects of the study of 4 classes available. Before conducting the study, the pre-test was taken to see how the classical teaching and learning activities made an impact to students' reading comprehension. And the post-test was held as the evaluation and comparison with different approaches.

\section{FINDINGS}

To obtain the objective results and to see if the strategy had worked appropriately according to the formulated plan, the teacher conducted a formative test during the learning experience which was the simplest mode to assess students and to get feedback on the program at the same time. The test papers were collected after both pre-test and post-test. Scoring was also done by the teacher. As both evaluations had the same materials and questions, it was obviously easy to 
highlight changes in students' answers as well as their progress in scores. There were 30 questions to answer, consisting of short answers, completing data in a table and open-ended questions. Therefore, a maximum score for each participant was 100 points.

The scores were then inputted into a table for data analysis and differences of the result are displayed in this table below.

\begin{tabular}{|l|c|c|}
\hline \multicolumn{1}{|c|}{ Result } & Pre-Test & Post-Test \\
\hline Highest score & 77 & 100 \\
\hline Lowest score & 23 & 17 \\
\hline Number of students whose scores are above the average & 18 & 19 \\
\hline Number of students whose scores are lower than the average & 16 & 15 \\
\hline Class average & 53 & 77 \\
\hline Number of students with upgraded scores & & 32 \\
\hline Number of students with degraded scored & & 2 \\
\hline Individual score progress by average (points/100) & & 21,67 \\
\hline
\end{tabular}

The pre-test session started with video playback before the reading session began. It was a strategy to link students' prior knowledge to the topic they were going to discuss. What made it classic was the way the teacher conducted these reading activities. Students would just sit still, read and answer questions without the teacher trying to link or elaborate any opinions. The result obtained from the pre-test showed that the class reached a relatively low average point which was only 53.

During the process, the teacher observed and assessed students' individual performance by analyzing each mind map, its extension and the explanation about the ideas made by students. This helped the teacher identify every weakness and strength in students' informational text proficiency. Another assessment was also conducted during the discussion to check for the interest, social and communication skills. Another one was during the wall magazines feedback and scoring session to assess their oral presentation skills. The teacher had to realize a single limitation that this type of observation could be very time-consuming as we would have to spend relatively more time assessing many aspects. It was also challenging to identify the cause of a certain action as there could be many explanations related to the action.

The post-test was taken to the whole class, which was examined to inspect whether the significant result could be accomplished in their reading comprehension level. It was also obtained another fact related to the score comparison after the process. The number of students who obtained better results was 32 students and 2 students were found to get their scores degraded. This data showed an increase in the individual progress of 21.67 points compared to previous result (by average).

Since there were not only academic assessments managed in this study, the teacher also took notes as references for classroom observations. It was found that students with better reading experience and habits would find it easier to get the gist and understand the context. They developed better reading comprehension as they were directly influenced by some references before than ones who did not have any similar background. They scored better on both tests with relatively difficult vocabulary with words that had never been taught as they were used to connect any words with their context.

\section{DISCUSSION}

According to the result, 2 students did not score as much expected, as their scores were degrading. The questions were: Was this type of learning activity such a difficult experience 
for them to follow as this might be a little more complicated than the classical one? Was the text getting more complex if it was delivered in a different particular way? Were their learning styles not suitable for this activity?

The teacher analyzed and identified the problems that occurred. The first student was getting 50, degraded from 57. On the post-test day, she was diagnosed with light fever which might affect her performance during the assessment. While the second student who got 17, degraded from 23 was diagnosed inclusive, he encountered a problem with his cognitive skill, emotional and adaptive social skill where actually, special evaluation and curriculum should always be designed exclusively to meet his academic targets. In this case, he was not excluded since the study aimed at exploring strategies for all as a homogenous community of fourth grade.

In general, there were many factors affecting students' involvement and engagement with their learning. It was something relatively new to them, as they might not experience this arrangement before. They could have had guided reading and making mind maps in the previous class yet this integrated experience has promoted motivational skills to obtain better reading interest. We were able to witness it by having students actively participated in any steps of this activity, no one looked unhappy with the situation, et cetera.

The first thing to concern was students' vocabulary before being exposed to new informational text. Prior exposure to leisure reading as they experience in reading fictional books was possibly one of the best ways to acquire new vocabulary. It produced great significance when the teacher had to evaluate the academic performance and result. We might begin with drenching students in informational text within the context of fictional stories. They would be introduced to more complex structures and vocabularies without difficulties.

This means that one of the most important duties for primary school teachers is that they must be able to introduce the astonishing world of reading to students they teach. We may start from nursery rhymes, bedtime stories, classic fairytales that would attract students' interest to read, make it their daily needs and to share that reading is not depressing, it is a pleasure. Showing them how much we are enthusiastic about reading by bringing our favorite books to class and by sharing each other favourites as well as connecting the moral of the story to their lives. In short, we might say that to adapt to the academic language environment, students are encouraged and supported to grow their vocabulary by being their role models in literacy.

Another finding, the classroom was a kind of learning environment where students hadn't been adequately exposed to daily literacy. Books, magazines, articles were things they rarely get in touch with regularly. Informational texts have become a challenge to understand as they ought to comprehend theories, concepts, symbols and definitions of new knowledge they have to master to succeed academically. 15 minutes of reading time in the class was not taken seriously, being replaced by lining up and other class rituals which consumed a lot of time.

During the discussion, some students were initiative by starting the conversation so everyone would be involved in social interaction to shape their understanding together. But their knowledge and vocabulary were limited, they couldn't make it connect the context. Some of them were easy to grasp the keyword, some of them were only exposed to fictional vocabularies and the rest were just following and sometimes giving opinions using their native language. A possible reason might be that students paid attention mostly to the information that was questioned for the tasks which included keywords, vocabulary, definition, and examples but they paid less attention to the context. So, if they had a rich academic vocabulary and used to read many references, they would eventually comprehend the context through the texts given. 
To undergo joyful learning, this board-based learning experience has enabled the teacher to manifest teaching strategies despite the limited resources and also students to develop and their reading, communication, and social skills. It has helped students become familiar with the keywords or main ideas of an informational paragraph or a text one. More importantly, it facilitated students with livelier, more-opened, interactive, and enjoyable communication and social atmosphere of learning.

The findings have also revealed that the current teaching strategies could initiate a more pleasant learning experience. The feedback that teacher found were varied with students elaborating ideas, giving comments to each other opinions and correcting students' conclusions presented in their projects. Peer assessment, besides teacher assessment, was found to be a relatively effective way to achieve intended learning outcomes.

\section{CONCLUSION}

Exploring ways to create joyful learning and analyzing their impacts on students' information literacy interest and academic results in a primary institution were the aims of the study. Different strategies used in the classroom were integrated and applied to provide students with new experiences and to suggest recommendations for peer teachers or other practitioners to cope with the intended learning outcomes.

The findings were used to provide variety in teaching and learning for peer teachers. As the questions, it may be concluded that:

1. This board-based learning experience has improved students' literacy interest compared to classical teaching and learning activities, proven by a livelier learning atmosphere.

2. This board-based learning experience has improved students' academic results compared to classical teaching and learning activities, proven by the progress in students' average scores.

The findings of this study indicate that this board-based learning experience has represented positive impacts toward the improvement of students' information literacy interest and academic results, but it may not be that effective if it is not conducted without the teacher's supervision. At some points, it was going to be a teacher-centered which should be shifted to a student-centered approach and vice versa. The teacher would be the facilitator, motivator, lecturer and prize giver. Students were motivated to read, to discuss, to create wall magazines creatively and to be involved in all activities guided by the teacher. They would be less motivated once they found another difficult word without their teacher was not being by their side as they still thought the answers were not in the text. The teacher should always be supposed to support how students come up with ways to connect main ideas, supporting ideas and blend them into the context. As a result, this activity has stimulated students to use mind map strategy to locate keywords and to link them with details in an informational text which can be done individually, resulting in the progress of individual average score which reached 21.67 points overall.

To sum up the reading comprehension assessment, we must perceive that proficiency is not a single action to evaluate once in a time, but it should be done continuously as long as students learn to keep track of their growth. This data will be used as our guide to create instructional decision-making. Teachers do have the means to assess different reading comprehension by using varied procedures. Students will not realize this as they are doing a way of thinking exploration.

Based on these findings, as the conclusion, it might be said that the teacher should be able to enhance their teaching skill by integrating any teaching strategies. Classical teaching and learning activities will not be considered as a boring experience as we thought it always was. It 
would be exciting if we integrate many strategies to facilitate various learning styles, especially with the intervention of digital applications. Even though all schools are not digitally supported but the teacher should always discover a way to eliminate this gap.

\section{REFERENCES}

Blanchett, H., Powis, C., \& Webb, J. (2012). A guide to teaching information literacy: 101 Practical tips. Facet Publishing.

Gunning, T. (2010). Reading comprehension boosters. Jossey-Bass.

Hepworth, M., and Walton, G. (2009). Teaching information literacy for inquiry-based learning. Chandos Publishing.

Klingner, J.K. (2004). Assessing Reading Comprehension. Assessment for Effective Intervention, 29 (4), 59-70. Retrieved from http://aei.sagepub.com

Lanning, S. (2012). Concise guide to information literacy. Libraries Unlimited.

Ren, J \& Wang, N. (2018). An Experimental Study of College English Teaching under The Production-Oriented Approach in NCEPU. Journal of English Language and Literature, 10(3), 1065-1069.

Walsh, J. (2011). Information literacy instruction. Chandos Publishing. 